\title{
Cardiac Ion Channel Genes
}

\section{Soon to Be Completely Analyzed?}

\author{
Andreas E. Busch \\ DG Cardiovascular Diseases, Hoechst Marion Roussel, Frankfurt am Main, Germany
}

The present issue of Cellular Physiology and Biochemistry is dedicated to important cardiac ion channels, their function in (patho-) physiology and their pharmacology. As the number of identified cardiac ion channel genes is enormous [1], this review can only be meant to cover in detail a small portion of them. The review gives the most recent update on the research on these putative drug targets for arrhythmias, coronary heart disease and heart failure.

After all the discoveries on ion channels in the past 15 years, one may ask the question 'What is left to be done?' Indeed, we can assume that within the next 3 years because of the completion of the Human Genome Project all genes for cardiac ion channels will have been identified. However, it is worthwhile to point out that the identification of an ion channel gene is only the first step on a rocky road to complete our understanding on the role and function of a particular channel. What questions are the most urgent to ask after identification of a novel gene upon an-

\begin{tabular}{ll}
\hline KARGER & (1) 1999 S. Karger AG, Basel \\
$\begin{array}{l}\text { Fax +41 61306 1234 } 34-8987 / 99 / 0095-0177 \$ 17.50 / 0 \\
\text { E-Mail karger@karger.ch } \\
\text { www.karger.com }\end{array}$ & $\begin{array}{l}\text { Accessible online at: } \\
\text { www.karger.com/journals/cpb }\end{array}$
\end{tabular}

swering the most obvious one for basic channel properties? Certainly, the analysis of its tissue distribution, the regulation of protein function and expression under physiological and pathophysiological conditions and the composition of the channel complex (is it a hetero- or homopolymeric channel) will play a crucial role in identifying a channel as a putative new drug target. Many of the above criteria are covered by the reviews of this issue.

In their review, Ludwig and co-workers describe the most recent work on the cardiac pacemaker current, which is already known for more than 20 years at the cellular level, but which was cloned only recently. Its intriguing properties, such as regulation by cAMP, high extracellular potassium and an increased protein expression in hypertrophied heart indicate an important role for diverse pathophysiological conditions.

A channel which is known much longer is the cardiac Na current responsible for action potential depolarization. Schreibmayer reviews the most recent findings of direct $\mathrm{Na}$

A.E. Busch
DG Cardiovascular Diseases
Hoechst Marion Roussel
D-65926 Frankfurt am Main (Germany)
Tel. +49 69305 13547, Fax +49 6930516393

DG Cardiovascular Diseases

D-65926 Frankfurt am Main (Germany)

Tel. +4969305 13547, Fax +496930516393 
channel regulation and the role of individual subunits in the channel complex during regulation.

In their review, Mitcheson and Sanguinetti analyze the role of $\mathrm{I}_{\mathrm{Ks}}$ and $\mathrm{I}_{\mathrm{Kr}}$ for action potential repolarization. The subunits underlying these ion conductances were the first $\mathrm{K}$ channel genes which were identified to cause a genetic defect, the so-called long QT syndrome (LQT), a disease which can prompt deadly arrhythmias.

Nattel and colleagues focus on the role of ultrarapidly activating $\mathrm{K}$ channels. Although great progress has been made to establish the molecular basis for these channels in distinct cardiac tissues, it is still not clear what $\mathrm{K}$ channel subunit composition is responsible for the rapidly activating $\mathrm{K}$ channel in atrium and ventricle from distinct species including man.

Much attention has been paid to cardiac $\mathrm{K}_{\mathrm{ATP}}$ channels as they can link the metabolic state of the cell directly to the action potential duration. Their putative involvement in ischemia-induced arrhythmias as well as their contribution to preconditioning is discussed in detail in the review by Gögelein's group.

Another channel of great importance for heart function and as a drug target is the Ltype $\mathrm{Ca}$ channel. Its multiple regulation by a great diversity of second messengers is dis- cussed by Striessnig. The review also points out that there is still room for L-type channel blockers with novel blocking mechanisms.

The final review by Freichel and co-workers deals with store-operated cation channels (SOC). These channels certainly are the least characterized channels in spite of their importance for a great variety of cell functions in various tissues. Many questions regarding the subunit composition of SOC remain without answers, and from this exciting channel family numerous new insights can be expected over the next years.

In summary, the present issue of Cellular Physiology and Biochemistry gives a detailed overview of important families of cardiac ion channels. Within the next 3 years the molecular identification of all cardiac ion channels may indeed take place. However, until the complete picture of structure, function, (patho-)physiological role and pharmacology of ion channels will be analyzed, a tremendous amount of research will have to be done.

\footnotetext{
Reference 1 Carmeliet E: Cardiac ionic current and acute ischemia: From channels to arrhythmias. Physiol Rev 1999; 79:917-1017.
} 